\title{
Enhancing the effectiveness of the balanced scorecard with scenario planning
}

\begin{abstract}
Purpose: This paper aims to propose the idea of linking the use of the balanced scorecard with scenario planning. Scenario planning emphasizes the development of a strategic plan that is robust across different scenarios. This ensures that the strategy implemented using the balanced scorecard is linked to external conditions and takes into consideration the expected changes in the environment.

Design/methodology/approach: This paper examines the criticisms of the balanced scorecard and proposes the use of scenario planning as a way of overcoming some of these limitations.

Findings: It argues that the use of scenario planning is capable of overcoming the lack of external orientation in the balanced scorecard. Scenario planning also helps make the balanced scorecard more reflective of changes that may appear in the future. This ensures that the scorecard developed is not merely a linear extension from the present.

Research limitations/implications: Studies need to be undertaken to examine whether integrating scenario planning with the balanced scorecard leads to more effective strategy implementation.

Practical implications: Adopters of the balanced scorecard need to recognize that developing a balanced scorecard system needs to be preceded by a strategy formulation process that incorporates an understanding of how future events may evolve. This can be achieved using scenario planning.
\end{abstract}

Originality/value: This study is probably the first attempt to link the implementation of the balanced scorecard and scenario planning.

Keyword: Balanced scorecard; Business planning; Business development 